\title{
PENGARUH PAKET MOBILISASI TERHADAP STATUS FUNGSIONAL PASIEN STROKE
}

\author{
Leli Mulyati, Hermansyah \\ Politeknik Kesehatan Kementerian Kesehatan Bengkulu, Jurusan Keperawatan, \\ Jalan Indragiri Nomor 03 Padang Harapan Bengkulu \\ liemulya@gmail.com
}

\begin{abstract}
Patients who got stroke should be took rehabilitation program. Furthermore, the ability for life reorganization to reach optimal health level. Especially for neurologic function after stroke attacked, for preventing disability and gain quality of their life. Nursing intervention at acute phase is important to establish for supporting reorganization of patient functions. One of that interventions is training the patient to do structured early mobilization. Aims of this study is to identified influenced of early mobilization against functional state of patient who got stroke. This was a descriptive study, a quasi experimental study. There were two group of study, divided to intervention group and control group. The samples of this study were stroke patient at Stroke Unit in M.Yunus Hospital of Bengkulu with total amount 64 respondents, wich picked by consecutive sampling. Measurement of functional status using the NIHSS score, which was measured on admission to hospital and the time the patientat discharge. The results showed an average NIHSS scores of stroke patients on admission is 11.56, SD 5.58 (moderate stroke). Meanwhile,the average NIHSS score when out of the hospital was 8.89, SD 7.6 (moderate stroke).Mean score for improved NIHSS patient who done structured training of mobilization is 4.87, SD 4.42 and score for patient who didn't do training is 0.313 , SD 4.46. After statistic test showed that $p$ value $=0.000<$ alpha. It's mean that there were significantly differences between NIHSS score for the patient who got structured early mobilization and who didn't. Structured early mobilization must be establish, and it's need collaboration from patient and family.
\end{abstract}

Key words :early mobilization, functional status, stroke

\begin{abstract}
Abstrak : Pasien yang mengalami stroke harus berupaya untuk mengoptimalkan kembali fungsi neurologis pasca serangan untuk mencegah kecacatan dan meningkatkan kualitas hidup pasien. Tindakan keperawatan fase akut yang dapat dilakukan untuk menunjang pengembalian fungsi tersebut adalah pelaksanaan mobilisasi dini secara terstruktur. Tujuan penelitian untuk mengidentifikasi pengaruh mobilisasi dini terhadap status fungsional pasien stroke. Rancangan penelitian ini adalah penelitian quasy eksperimental dengan kelompok intervensi dan kontrol. Pasien stroke akut di unit stroke Rumah Sakit M.Yunus Bengkulu sebagai sampel sebanyak 64 orang. Pengambilan sampel consecutive sampling. Intervensi dilakukan pada kelompok eksperimen selama pasien dirawat. Pengukuran status fungsional menggunakan skor NIHSS, yang diukur saat pasien masuk RS dan saat pasien keluar RS. Hasil penelitian didapatkan skor rata-rata NIHSS pasien stroke saat masuk RS adalah 11.56, SD 5.58 (stroke sedang), sedangkan skor ratarata NIHSS saat keluar dari RS adalah 8.89, SD 7.6 (stroke sedang). Rata-rata skor perbaikan NIHSS pasien stroke yang dilakukan mobilisasi dini adalah 4.87, SD 3.42 dan rata-rata skor NIHSS pada pasien yang tidak dilakukan mobilisasi dini sebesar 0.313, SD 4.46. Hasil uji statistik didapatkan nilai $\mathrm{p}=0.000$ artinya ada perbedaan signifikan rata-rata skor NIHSS pasien stroke antara kelompok yang dilakukan mobilisasi dini dan tidak dilakukan mobilisasi. Mobilisasi dini terstruktur harus dilaksanakan secara rutin dengan kerjasamadari pasien dan keluarga.
\end{abstract}

Kata kunci : mobilisasi dini, status fungsional, stroke

Masalah-masalah neurologi dapat mengakibatkan perubahan dalam kognitif, sensori, fungsi neuromuscular dan harga diri rendah. Masalah neurologi juga dapat menyebabkan pasien menderita komplikasi penyakit yang parah dan kematian. Hal tersebut bisa disebabkan oleh penyakit stroke, cedera kepala, tumor otak dan abses otak yang dapat meningkatkan tekanan 
intrakranial. Disfungsi neurologi yang permanen atau kematian dapat dicegah dengan mengetahui penyakit secara dini serta penanganan cepat dan tepat oleh tim kesehatan multi disiplin.

Dewasa ini yang menjadi perhatian utama pada masalah keperawatan neurologi adalah penyakit stroke. Data WHO tahun 2007, menunjukkan 15 juta orang menderita stroke di seluruh dunia setiap tahun. Sebanyak 5 juta orang mengalami kematian dan 5 juta mengalami kecacatan yang menetap, stroke merupakan penyakit nomor tiga yang mematikan setelah jantung dan kanker. Insiden stroke diperkirakan lebih dari 750.000 per tahunnya dengan $200.000 \mathrm{jiwa/tahun} \mathrm{serangan} \mathrm{stroke}$ berulang, sebagian atau lebih pasien stroke akan mengalami ketergantungan secara fisik bahkan kematian (Price \& Wilson, 2006).

Menurut survei tahun 2004, stroke merupakan pembunuh nomor satu di RS pemerintah di seluruh penjuru Indonesia. Diperkirakan setiap tahun terjadi 500.000 orang penduduk Indonesia terkena serangan stroke dan sekitar $25 \%$ atau 125.000 orang meninggal dan sisanya mengalami cacat ringan atau berat (Yastrokei, 2007, 2020). Stroke merupakan penyebab kematian terbesar di rumah sakit dan penyebab utama kecacatan pada kelompok usia dewasa. Serangan stroke lebih banyak pada laki-laki yang terjadi pada usia di bawah 45 tahun sebanyak $11,8 \%, 54,2 \%$ pada usia 45-64 tahun serta di atas usia 65 tahun sebanyak 33,5\% (Rasyid, et al, 2007).

Stroke adalah suatu kumpulan gejala klinis yang berkembang cepat akibat gangguan fungsi otak secara vokal atau global yang berlangsung selama 24 jam/lebih atau menyebabkan kematian, tanpa adanya penyebab lain yang jelas selain gangguan vaskuler (WHO, 1986, dalam Rasyid, et al., 2007). Stroke atau Cedera Serebrovaskuler (CVA) merupakan ketidaknormalan fungsi Sistem Saraf Pusat (SSP) yang disebabkan oleh gangguan kenormalan aliran darah ke otak. Stroke dapat dibagi menjadi dua kategori utama, yaitu strokeiskemik $(85 \%)$ terjadinya penyumbatan pembuluh darah, terjadi penurunan perfusi yang nyata dan strokehemoragik $(15 \%)$ terjadinya ektravasasi perdarahan ke dalam otak atau ruangan sub araknoid (Smeltzer et.al, 2008).

Stroke menyebabkan berbagai defisit neurologi, bergantung pada lokasi lesi (daerah pembuluh darah yang tersumbat), ukuran area yang perfusinya tidak adekuat dan jumlah aliran darah kolateral (sekunder). Manifestasi klinis dari stroke itu antara lain: kehilangan kekuatan motorik, kehilangan komunikasi, gangguan persepsi, kerusakan fungsi kognitif dan efek psikologik, disfungsi kandung kemih. Sekitar 30\%-40\% penderita stroke dapat sembuh sempurna (bisa bekerja seperti biasa) asalkan penanganan terhadap mereka dilakukan dalam jangka waktu 6 jam setelah terjadinya serangan agar pasien tidak mengalami kecacatan. Bahkan ada yang berpendirian bahwa penderita stroke dapat sembuh bila ditangani kurang dari 3 jam setelah terjadi serangan (Smeltzer et.al 2008; Black \& Hawks, 2005; Ignativius \& Workman, 2006; Hickey, 2003; Lemone \& Burke, 1996; Polaski \& Tatro, 1996).

Gejala sisa seperti jalannya pincang atau berbicaranya pelo masih bisa disembuhkan. Sebagian besar penderita stroke datang ke rumah sakit setelah 48 jam terjadinya serangan. Ini sangat memprihatinkan mengingat Insan Pasca Stroke (IPS) biasanya merasa rendah diri dan emosinya tidak terkontrol dan selalu ingin diperhatikan.

Berdasarkan masalah dan dampak biopsiko-sosial-spiritual akibat stroke dalam kondisi akut maupun lanjut, maka perlu ditangani sebaik mungkin oleh tim kesehatan salah satunya termasuk perawat. Dengan demikian sangat dibutuhkan peran perawat yang professional serta mampu memberikan asuhan keperawatan secara cepat, tepat dan komprehensif sehingga dapat mencegah kecacatan dan kematian (Smeltzer et.al, 2008).

Tindakan keperawatan pada pasien stroke dimaksudkan untuk mengurangi dan mencegah beratnya gejala sisa pasca stroke. Salah satu yang bisa dilakukan adalah dengan melakukan mobilisasi dini fase akut stroke. Tindakan ini meliputi elevasi kepala 30 derajat, miring kiri dan kanan, serta melakukan ROM pasif. Pemantauan kondisi pasien dapat dilakukan 
dengan mengevaluasi status fungsional menggunakan National Institute of Health Stroke Scale (NIHSS) yang sudah diketahui validasinya baik (Joseph, 2004; Damhudi, 2009).

Kejadian stroke di Propinsi Bengkulu menunjukkan angka yang cukup tinggi. Di RSUD dr. M.Yunus yang merupakan Rumah Sakit rujukan untuk Pemulihan Stroke di propinsi Bengkulu, memiliki angka kunjungan stroke 612 pasien $(10,09 \%)$ dari 6068 pasien (RSUD Dr. M. Yunus, 2011) dengan kunjungan stroke berulang sebesar 367 pasien $(59,98 \%)$. Perawat di ruang stroke RSUD Dr. M. Yunus Bengkulu masih menggunakan mobilisasi yang rutin namun tidak terstruktur sehingga status fungsional pasien stroke masih rendah.

Hasil penelitian Husni, et al (2011) di ruangan stroke RSUD Dr. M. Yunus Bengkulu menunjukkan bahwa rata-rata status fungsional pasien stroke pada saat awal masuk adalah $6 \pm 4,068$, sedangkan pada saat kontrol ke rumah sakit rata-rata status fungsional pasien stroke

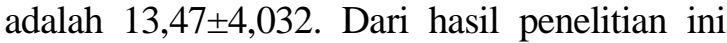
juga disimpulkan bahwa tidak terdapat perbedaan yang signifikan status fungsional pasien sebelum mendapatkan discharge planning pada kelompok intervensi dan kontrol $(\mathrm{p}=0,482)$, demikian juga setelah mendapat discharge planning $(\mathrm{p}=0,426)$. Hasil penelitian multivariate juga menunjukkan bahwa tidak ada pengaruh yang signifikan status fungsional pada kelompok intervensi dan kontrol setelah diberikan discharge planning $(\mathrm{p}=0,931)$ setelah dikontrol oleh variabel umur dan tingkat pendidikan. Tujuan penelitian ini adalah mengetahui pengaruh paket mobilisasi terhadap status fungsional pasien stroke di ruang rawat stroke RSUD Dr. M. Yunus Bengkulu.

\section{BAHAN DAN CARA KERJA}

Jenis penelitian yang digunakan adalah quasy eksperimen dengan rancangan Preposttest with control group. Populasi dalam penelitian ini adalah seluruh pasien stroke yang dirawat di ruang rawat inap stroke RSUD Dr. M Yunus Bengkulu pada tahun 2013. Sampel dalam penelitian ini adalah stroke yang dirawat di ruang rawat inap stroke RSUD Dr. M Yunus
Bengkulu pada tahun 2013, dengan tehnik pengambilan sampel consecutive sampling dengan besar sampel 32 kelompok intervensi dan 32 kelompok kontrol. Kriteria inklusi dalam penelitian ini adalah bersedia menjadi responden dan pasien stroke fase akut $(<24$ jam serangan).

Instrumen penelitian untuk mengukur status fungsional perifer pasien stroke diukur menggunakan format penilaian NIHSS sebelum dan sesudah intervensi paket mobilisasi pasien stroke. Intervensi dengan menggunakan paket mobilisasi untuk pasien stroke terdiri dari pengaturan posisi tidur, latihan pasif anggota gerak atas dan bawah, latihan aktif anggota gerak atas dan bawah. Analisis data secara univariat dan bivariat dengan menggunakan uji $t$ dependent (one tail) pada $\alpha 5 \%$.

\section{HASIL}

\section{Analisis Univariat}

Analisis univariat pada penelitian ini untuk melihat nilai distribusi frekuensi jenis kelamin, frekuensi serang stroke, penyakit penyerta, kebiasaan merokok, dan jenis stroke pada pasien stroke, sedangkan pada variabel dengan jenis data numerik hasil analisis disajikan dengan adalah nilai mean median, nilai minimalmaksimal, standardeviasi, dan $95 \%$ Confidience Interval (CI) dari mean sebelum dan sesudah dilakukan paket mobilisasi pada pasien stroke.

Tabel 1. Distribusi Responden Berdasarkan Jenis Kelamin, Frekuensi Serangan, Penyakit Penyerta dan Riwayat Merokok, Jenis Stroke

\begin{tabular}{lcc}
\hline \multicolumn{1}{c}{ Variabel } & Frekuensi & Persentase \\
\hline Jenis Kelamin & 31 & $48.4 \%$ \\
Laki-laki \\
$\begin{array}{l}\text { Perempuan } \\
\text { Frekuensi serangan }\end{array}$ & 33 & $51.6 \%$ \\
$\begin{array}{l}\text { Pertama } \\
\text { Serangan Ulang }\end{array}$ & 52 & $81.2 \%$ \\
$\begin{array}{l}\text { Penyakit penyerta } \\
\text { Tidak ada }\end{array}$ & 12 & $18.8 \%$ \\
Ada & 14 & $21.9 \%$ \\
Merokok & 50 & $78.1 \%$ \\
Tidak & & \\
Ya & 33 & $51.6 \%$ \\
Jenis stroke & 31 & $48.4 \%$ \\
Non Haemoragik & & \\
Haemoragik & 26 & $40.6 \%$ \\
\hline
\end{tabular}


Berdasarkan tabel 1 Di dapatkan data bahwa sebagian besar (51.6\%) berjenis kelamin perempuan, dan tidak merokok, hampir seluruh $(81.2 \%)$ mengalami stroke serangan pertama, sebagain besar (59.4\%) mengalami stroke Haemoragik, serta sebagian besar mempunyai penyakit penyerta $(75.1 \%)$.

Tabel 2. Rata-rata Usia Responden

\begin{tabular}{lllll}
\hline Variabel & Min & Max & Mean & SD \\
\hline Usia & 34 & 85 & 56.8 & 12.343 \\
\hline
\end{tabular}

Berdasarkan tabel 2 diketahui bahwa usia rata-rata pasien stroke 56.8 tahun, usia termuda 34 tahun dan usia tertua 85 tahun.

Tabel 3. Distribusi Rata-Rata Skor NIHSS Responden Saat Masuk dan Keluar RS

\begin{tabular}{ccccc}
\hline \multicolumn{1}{c}{ Skor NIHSS } & Min & Max & Mean & SD \\
\hline Saat masuk RS & 2 & 23 & 11.56 & 5.58 \\
Saat keluar RS & 0 & 28 & 8.89 & 7.6 \\
\hline
\end{tabular}

Berdasarkan tabel 3 dapat dijelaskan bahwa skor minimal NIHSS pasien stroke saat masuk RS adalah 2 (stroke ringan) dan skor maksimalnya 23 (stroke berat) dengan nilai rata-rata skor NIHSS 11.56 (stroke sedang). Sedangkan skor NIHSS saat keluar dari RS skor minimal 0 (Pasien pulih), skor maksimal 28 (stroke berat) serta nilai rata-rata skor NIHSS saat keluar RS adalah 8.89 (stroke sedang).

\section{Analisis Bivariat}

Tabel 4. Distribusi Rata-Rata Skor NIHSS Pasien Stroke Menurut Pelaksanaan Mobilisasi Dini

\begin{tabular}{lccccc}
\hline \multicolumn{1}{c}{ Variabel } & N & Mean & SD & SE & P \\
\hline $\begin{array}{l}\text { Paket } \\
\text { Mobilisasi }\end{array}$ & 32 & 4.87 & 3.42 & 0.60 & 0.000 \\
$\begin{array}{l}\text { Mobilisasi } \\
\text { Rutin RS }\end{array}$ & 32 & 0.313 & 4.46 & 0.78 & \\
\hline
\end{tabular}

Berdasarkan tabel 4 dapat dijelaskan bahwa rata-rata skor perbaikan NIHSS pasien stroke yang dilakukan mobilisasi dini adalah 4.87, dan rata-rata skor NIHSS pada pasien yang tridak dilakukan mobilisasi dini sebesar 0.313. Hasil uji statistik didapatkan nilai $\mathrm{p}=$ 0.000 artinya ada perbedaan signifikan rata-rata skor NIHSS pasien stroke antara kelompok yang dilakukan mobilisasi dini terstruktur dan tidak dilakukan mobilisasi dini terstruktur.

\section{PEMBAHASAN}

Berdasarkan tabel di atas dapat dijelaskan bahwa sebagian besar pasien stroke $(51.6 \%)$ berjenis kelamin perempuan, dan tidak merokok, hampir seluruh $(81.2 \%)$ mengalami stroke serangan pertama, sebagain besar mengalami stroke Haemoragik (59.4\%), serta sebagian besar mempunyai penyakit penyerta (75.1\%).

Berbagai penelitian yang telah dipublikasikan menyatakan bahwa merokok merupakan salah satu faktor kuat penyebab stroke khususnya perdarahan intra serebral dan subaraknoid. Hal ini dihubuingkan dengan peningkatan tekanan darah akut yang menyebabkan terjadinya ruptur arteri. Mekanisme lainya dengan terjadinyas proses arteriosklerosis yang progresif pada perokok (Barnes, et al 2005).

Hipertensi merupakan faktor risiko terbanyak dan dapat dimodifikasi pada pasien stroke, dan dihubungkan dengan perdarahan otak. Faktor ini juga sulit dipisahkan karena interaksi dengan faktor risiko lain seperti usia dan atrial fibrilasi. Berbagai penelitian menyatakan bahwa peningkatan tekanan diastolik 10 kali berisiko menyebabkan stroke. Dan obat-obat antihipertensi mengurangi risiko stroke (Barnes et al, 2005).

Berdasarkan tabel diketahui bahwa usia rata-rata pasien stroke 56.8 tahun, usia termuda 34 tahun dan usia tertua 85 tahun. Usia lanjut merupakan salah satu faktor predisposisi terjadinya stroke. Kondisi ini dihubungkan dengan terjadinya penurunan permeabilitas pembuluh darah sehingga terjadi kekakuan. Hal ini menyebabkan terjadinya peningkatan tekanan resistensi perifer yang pada akhirnya juga meningkatkan tekanan darah (Lemone \& Burke, 2006). Hasil ini sejalan dengan hasil penelitian Asna di $28 \mathrm{RS}$ di seluruh Indonesia yang menyatakan bahwa sebagian besar usia pasien stroke antara 45-64 tahun dan umur ratarata 58 tahun (Rosyid, 2007)

Berdasarkan hasil penelitian didapatkan bahwa skor minimal NIHSS pasien stroke saat masuk RS adalah 2 (stroke ringan) dan skor maksimalnya 23 (stroke berat) dengan nilai rata-rata skor NIHSS $11.56 \pm 5.58$ (stroke 
sedang), sedangkan skor NIHSS saat keluar dari RS skor minimal 0 (Pasien pulih), skor maksimal 28 (stroke berat) serta nilai rata-rata skor NIHSS saat keluar RS adalah $8.89 \pm 7.6$ (stroke sedang).

Berdasarkan hasil penelitian didapatkan bahwa rata-rata skor perbaikan NIHSS pasien stroke yang dilakukan mobilisasi dini adalah $4.87 \pm 3.42$, dan rata-rata skor NIHSS pada pasien yang tidak dilakukan mobilisasi dini sebesar 0.313 \pm 4.46 . Hasil uji statistik didapatkan nilai $\mathrm{p}=0.000$ artinya ada perbedaan signifikan rata-rata skor NIHSS pasien stroke antara kelompok yang dilakukan mobilisasi dini dan tidak dilakukan mobilisasi.

Mobilisasi terstruktur dan berulang meningkatkan potensi memori jangka panjang pada berbagai tingkat saraf pusat. Latihan juga meningkatkan produksi neurotransmiter seperti asetilkolin dan serotonin, meningkatkan sintesa neurotropine dan memicu terjadinya proliferasi dan daya tahan lebih besar pada sel progenitor hypocampus yang sangat penting untuk proses pembelajaran baru dan memory. Pembelajaran motorik adalah suatu rangkaian proses untuk mencapai kemampuan untuk menghasilkan kegiatan keterampilan atau perilaku kebiasaan melalui mekanisme memori prosedural. Proses ini terjadi dalam neuron dan koneksi sinapsnya dalam jaringan persarafan. Latihan secara konstan akan meningkatkan penampilan saat menghasilkan kembali gerakan keterampilan dan parameternya (Barner, et al, 2005).

Hasil ini sejalan dengan penelitian Rasyid dkk, 2007 yang menyatakan bahwa terdapaat perbedaan skor NIHSS antara pasien yang dirawat di unit stroke dengan di bangsal neurologi. Di unit stroke penurunan skor NIHSS berkisar 17.35 sampai 5.31 sedangkan pada bangsal neurologi berkisar antara 13.83 sampai 8.87. dan uji statistik t-test juga

\section{DAFTAR RUJUKAN}

Alexander, Fawcett, Runciman. 2000. Nursing Practice Hospital and Home the Adult, Second edition, Toronto. Churchill Livingstone.

Arjatmo Tjokronegoro \& Henrautama. 2002. Update In Neuroemergencies.BalaiPenerbit FKUI: Jakarta.

Barnes, et al. 2005. Recovery after stroke.New York: Cambrige University Press. menunjukan penurunan skor NIHSS unti stroke lebih bermakna dibandingkan bangsal neurologi. Berenhardt et al, (2009) menyatakan dalam penelitiannya bahwa: mobilisasi dini pada stroke akut belum bisa dibuktikan uji statistik secara signifikan keuntungannya terhadap pemulihan pasien stroke.

Telah diketahui secara jelas bahwa, reorganisasi fungsi otak akan bisa mencapai optimal setelah serangan stroke. Hal ini membutuhkan metode reorganisasi dalam rehabilitasi fisik dan membutuhan waktu khusus untuk berlatih, pekatihan kekuatan dan endurance, dan latihan aerobik. Frekuensi dan intensitas rehabilitasi dibutuhkan untuk meningkatkan tingkat energi pasien sehingga membutuhkan latihan fisik selama pasien dirawat dan setelah pulang (Carr \& Sheperd, 2011).

\section{KESIMPULAN}

Sebagian besar pasien stroke berjenis kelamin perempuan, dan tidak merokok, Hampir seluruh mengalami stroke serangan pertama, sebagain besar mengalami stroke Haemoragik serta sebagian besar mempunyai penyakit penyerta. Terdapat perbaikan skor NIHSS pasien stroke yang dilakukan mobilisasi dini terstruktur dibandingkan dengan skor NIHSS pada pasien yang tidak dilakukan mobilisasi dini terstruktur. Hasil uji statistik didapatkan bahwa ada pengaruh mobilisasi dini terstruktur terhadap peningkatan status fungsional pasien stroke.

Disarankan kepada perawat di ruangan stroke agar terus menerapkan mobilisasi dini terstruktur dalam perawatan pasien stroke akut dengan tetap melakukan pemantauan ketat status neurologi dan tanda-tanda vital pasien.

Bernhardt J, Thuy MN, Collier JM, Legg LA. 2009. Very early versus delayed mobilisation after stroke. Cochrane Database Syst Rev. 2009 Jan 21;(1):CD006187. doi: 10.1002/14651858. CD006187.pub2. 
Black, JM., Matassin E. 2002. Medical Surgical Nursing, Clinical Management for Continuity of Care.JB. Lipincott.co

Black, J, \& Hawks, J. 2009. Medical surgical nursing. (8 thed). Singapore: Elsevier Saunders

Bullock, Barbara. 2000. Focus on pathophysiology. Philadelphia.

Brunner \&Suddarth's . 1999. Textbook of Medical surgical nursing.Eighth Edition. Philadelphia. New York: Lippincortt.

Carr JH, Shepherd RB. 2011. Enhancing physical activity and brain reorganization after stroke.Neurol Res Int. 2011;2011:515938. doi: 10.1155/2011/515938. Epub 2011 Jul 3.

Chris Winkelman. Neurological Critical Care.American journal Of Critical care.Nopember 2000-volume 9 Number 6.

Computed Tomography,diambildari http:/en wiki/wikipedia/computed tomography.htm diambiltanggal 10 Februari 2006

Colmer, MR. 1995. Coronarys surgery for nurses.16th ed. Livingstone.

Doenges, Marylinn E. 2002. Nursing care plan: guidelines for Planning and documenting patient care. 3rd ed. FA. Davis

Hudak\& Gallo. $1997 . \quad$ KeperawatanKritis ;Pendekatankritis, Edisi VI - Volume Jakarta: EGC

Husni, dkk. 2011. Pengaruh Discharge Planning Terstruktur Terhadap Penurunan Risiko Kekambuhan, Length Of Stay Dan Peningkatan Status Fungsional Pada Pasien Stroke Iskemik Di RSUD M.Yunus Bengkulu. Risbinakes. Poltekkes Kemenkes Bengkulu.

Ignatavicius, D, \& Workman,. 2006. Medical surgical nursing : Critical thinking for collaborative care. 5th ed. St Louis, Missouri: Elsevier Inc.

Jean A. Proehl, RN, MN, CEN, CCRN.1999. Emergency Nursing Prosedur. W.B Saunders Company: Philadelphia.
Joseph V, et.al. 2004. Intracranial pressure/head elevation. Diambil 17 Februari 2006. http ://pedscm.wustl.edu/all_net/English/Neuropage/Prot ect/icp-Tx-3.htm

Luckman Sorensen. 1995.Medical Surgical Nursing, A PhsycoPhysiologic

LeMone, P \& Burke. 2006. Medical surgical nursing. Addison Wesley. New York Approach, 4th Ed,WB Saunders Company, Phyladelpia

2008. Medical surgical nursing : Critical thinking in client care. (4thed). Pearson Prentice Hall: New Jersey.

Morton, P.G. 2005. Critical care nursing : a holistic approach. 8thedition. Lippincott William \& Wilkins. Philadelphia.

Morton,P.Getall. 2005. Critical care nursing, a holistic approach. 8 th ed. Philadelphia: Lippincot.

Price, S.\&Wilson,L. 2002. Pathofisiology.Clinical concepts of deseaseproceses. Philadelphia: Mosby

.2006. Patofisiologis. Konsepklinis prosesproses penyakit.Edisike 6. Jakarta: PenerbitBukuKedokteran EGC.

Perry,A.G. \&Potter,P.A., 2008. Clinical nursing skill.St.Louis:Mosby

Rasyid, et al., 2007.Unit Stroke.ManajemenStrokeSecaraKomprehensif. Jakarta :BalaiPenerbitFakultasKedokteranUniversitas Indonesia.

RSUD Dr. M. Yunus Bengkulu. 2011. LaporanRuangStroke. RSUD Dr. M. Yunus Bengkulu.

Smeltzer, S, \& Bare. 2008. Brunner \&Suddarth's Textbook of medical surgical nursing. Philadelpia : Lippincott

Thompson, et all. 1997. Clinical Nursing, Fourth edition. Mosby. California.

UNC Hospital. 2005. Intracranial Pressure Monitoring.Diambil 17 Februari 2006.www. intracranial pressure monitoring. 